\title{
Recess as a Site for Language Play
}

\author{
JUNE COUNTRYMAN, MARTHA A. GABRIEL \\ University of Prince Edward Island
}

\begin{abstract}
Researchers in this study adopted an ethnomusicology perspective to explore the playground language and music-making practices of children at nine Canadian school playgrounds over a two-year period. Using non-participant observation the researchers found that school children (ages 5-12) engaged in multimodal and multi-vocal play as they manipulated language, chanted or sang with rhythmic speech, and combined language play with gestures and kinetic movements. The authors suggest a link between children's out-of-school literacies ('languaging' and 'musicking' on the playground) where children are active agents of their own learning - and children's potential in-school literacies.
\end{abstract}

\section{Recess as a Site for Language Play: Investigating Children's Multimodal Expressions}

The soundscape of a typical North American elementary school playground during recess is unmistakable: yelling, screeching, sharp calls to peers, wails of frustration, shouts of ecstasy, game cheers and more, an ever-shifting, polyphonic din accompanying children at play. This soundscape is remarkably similar from school to school and year to year and can easily be dismissed as sonic evidence of trivial activity, of play that is ephemeral and inconsequential beyond its function of providing children with short breaks from the rigors of formal schooling.

In this paper we invite our readers inside this ubiquitous soundscape, to consider examples of vocal play that are an omnipresent part of the noisy playground, and to ponder their significance. Paralinguistic soundings, speaking and singing are not discrete acts but rather exist on a continuum. Children slide along this continuum constantly, confidently, and unconsciously. During their self-directed play children manipulate language, using rhythmic speech, vocables and song, combined with gestures and kinetic movements. Children's multimodal vocal play seems to address a variety of needs: it signifies, amuses, attracts attention, claims status, teases, expresses emotions and fills in awkward social spaces. We suggest that this self-chosen, improvised language play also contributes to confident language use and literacy development.

\section{Musicke and Multimodality}

\section{Theoretical Orientations}

We focus on children's vocal play that can be labelled musical due to the manipulation of such features as vocal register, timbre, dynamics, pitch, metre, rhythmic 
organization and structural repetition at the level of a motif or phrase. We define our use of these musical terms, emphasizing with Finnegan (2002) that, "acoustic communicating through the voice is in fact a flexible process rather than fixed system" (p. 66).

Vocal register: a specific part of one's complete voice range. If we describe our typical speaking voice as comprising our middle register, we can also access a lower register (growly), a higher register, where both heightened speech and singing reside, and a still higher (scream) register

Timbre: the quality that enables us to distinguish one voice or sound from another, referred to as intonation in speech and tone colour in music

Dynamics: the louder/softer dimension of sound (volume)

Pitch: the higher/lower dimension of sound

Beat: regularly recurring temporal pulse in chanted speech and music

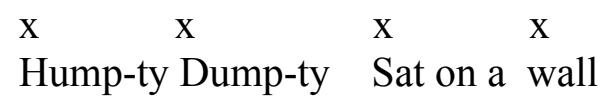

Metre: temporal organization created by regularly recurring accented beats, e.g.

$\begin{array}{ll}> & > \\ \text { Hump-ty Dump-ty } & \text { Sat on a wall }\end{array}$

Rhythmic organization: grouping of longer/shorter sounds and silences, relative to a felt sense of beat. Patel (2008) defined rhythm as "the systematic patterning of sound in terms of timing, accent and grouping" (p. 96).

Motif: a short sound pattern distinctive enough to be memorable and repeatable; also called a riff

Phrase: a longer sound pattern, roughly the length of a full breath. The phrase is considered to be a complete musical 'thought'.

Alcock (2008) used the ancient Greek word musike, which includes poetry, dance, drama and music - the temporal arts - to convey the holistic way that children draw on "time and movement experienced and represented aesthetically in musical pulse" (p.328). Musike perfectly captures the kinds of spontaneous behaviours we are investigating because musical language play rarely exists without gesture and physical movement. Further, musike includes the performance dimension of drama, poetry, dance, and music, an important dimension of the musical language play we examine here.

With musike, early Greek scholars were advancing a version of the concept we now recognize as multimodality. Multimodality, a domain of inquiry within social 
semiotic theory, "attends to meaning as it is made through the situated configurations across image, gesture, gaze, body posture, sound, writing, music, speech, and so on" (Jewitt, 2008, p. 246). In their play, children make meaning through the modal resources at their disposal: chiefly voice (across a wide expressive spectrum), gesture and movement, combined to communicate meaning.

Multimodal scholars examine how people make meaning (through representation, communication, and interaction) emphasizing that several modes, or semiotic resources, always coexist in any semiotic event (Hurdley \& Dicks, 2011; Jewitt, 2009; Kress, 2010). Jewitt provided four interconnected theoretical assumptions that help clarify this concept.

- Language is part of a multimodal ensemble. We seek to shine a light on the naturally multimodal nature of children's spontaneous language play, describing ways in which they incorporate multiple modes (sound, speech, song, gaze, gesture, mime, movement) in their communications.

- Each mode realizes different communicative work. This work is situated and social. We work to understand the contexts in which children's self-initiated language play occurs, acknowledging that our sense of what is going on is always partial.

- People orchestrate meaning through their selection and configuration of modesthe interaction between modes is a part of the production of meaning. Most striking in children's language play is the simultaneous use of multiple modes and the quicksilver nature of the play. This play, ebullient and often virtuosic, is evidence of communication skills that deserves educators' attention.

- The meanings of signs fashioned from multimodal semiotic resources are social. While we document both solitary and social language play on the playground, we recognize that both produce social meanings. (pp. 14-15, italics added)

Of the musical aspects of language play we define above, several are implicated in what Van Leeuwen (2009) called voice quality. He identified vocal range, loudness, rough, smooth and breathy voices and resonance (both characteristics help create timbre), and articulation (implicated in creating rhythmic patterns and metre), as contributing to voice quality, which, in turn, contributes to meaning-making. Van Leeuwen emphasized the physicality, materiality, and experiential nature of the voice and noted that voice quality is organized "not taxonomically, but parametrically, through a set of parameters which all have to always be chosen, but to different degrees" (p. 75). In their vocal play children are sounding identity and text synchronously.

\section{Communicative Musicality}

The concept of communicative musicality (Malloch \& Trevarthen, 2009, and particularly the work of Ellen Dissanayake, 2000; 2001; 2009a, b; 2011) influences our understanding of children's musical language play. Malloch and Trevarthen identified communicative musicality in the melodic and rhythmic co-creativity in mother/infant 
communication. Through this intentional communication mother and baby share "a sense of sympathy and situated meaning in a shared sense of passing time" (p. 4).

Dissanayake (2009a), who established that this mother/infant communicative musicality is a universal phenomenon, posited an evolutionary path from these interactions through ceremonial ritual to the temporal arts. She characterized the "temporally organized expressive vocalizations and movement" (p. 534) of mother/infant communication as proto-aesthetic because they are spontaneous (unself-conscious). Our ancestors gradually began to consciously use these "aesthetic predispositions" (2011, p. 57 ) in their ceremonial rituals, which evolved over millennia into the temporal arts.

In Art and Intimacy, Dissanayake (2000) argued that the arts evolved from the human needs for relatedness (the arts enhance mutuality) and for self-experience (the arts help us achieve experiences of meaning and personal competence). Her claims about our human instinct to "artify"- to employ affective aesthetic devices in our lives-are exemplified in children's spontaneous musicking. (Musicking is a term coined by Christopher Small (1998) to convey the important idea that music is a verb: its raisond'être is in the doing.) Dissanayake's wide-ranging body of work provides a multidisciplinary grounding from which to explore children's musical language play.

Play

An overarching view of play is provided by Biesty (2002) who argued that play "harmonizes two fundamental motivations, growth and belonging" (p. 44). Watching children's self-directed play, we witness the veracity of this observation. Growth encompasses at least three categories: developing expertise in physical pursuits (e.g. running, skipping, balancing), developing intrapersonal skills (e.g. managing emotions, enhancing self-efficacy), and developing social skills (e.g. choosing playmates, negotiating competition and conflict). The motivation to belong shapes these physical, personal, and social growth motivations within an arena of inclusion and exclusion, casting growth and belonging as "the yin and yang of play" (p. 48).

Research into the role of play in human development is inconclusive, in part because of a lack of agreement on a definition of play. Pellegrini (2009) suggested core criteria for delimiting play, two of which are its voluntary nature and its nonfunctionality. Players voluntarily choose to "engage in some social, locomotor, fantasy or objectdirected activity that is not directly functional" (p. 132). Further, the play contains elements that are exaggerated, segmented, and nonsequential. Pellegrini emphasized that because children are free from concerns about the specific usefulness of play they can experiment, which results in "behavioral and cognitive flexibility" (p.132) - in other words, play's lack of a specific function enables it to provide important benefits.

These insights into the nature of play help contextualize the vocalized play we describe below. Musical language play forms the soundtrack of physical, psychological, and social growth tendencies, where children announce the desire to belong and the satisfaction of belonging as well as the need for comfort or diversion when they experience exclusion or rejection. These voluntary expressions, which feature aspects of 
repetition, segmentation, and exaggeration, communicate information, emotion-states, and sociality.

\section{Method}

We examine instances of language use observed during non-instructional outdoor recess play at nine elementary schools where children are ages 5-12 years. This work is part of our broader exploration into the nature of children's self-directed play, at both childcare centres and elementary school playgrounds, in which we employ what Campbell $(2003 ; 2010)$ described as an ethnomusicological method. We document and analyze the nature of this spontaneous musicking and draw from our analysis implications for educational practice in both language and music. We know that voice play serves both personal and social uses for children and is a natural part of their multimodal approach to meaning-making and communication. We believe, as many educators do, that children's rhythmic and melodic play is also essential to their language and literacy fluency.

Our research team consisted of two academics (author one, music education and author two, literacy education) and two music student research assistants supported by the Advanced Interdisciplinary Research in Singing (AIRS) project, a SSHRC-funded MCRI research program. We received ethical approval from our university and two public school board to conduct naturalistic, non-participant observations of children during their outdoor playtime. While our project includes audio and video taping and interviews with children, the focus in this paper is on the non-participant observation aspect of the study because we seek to examine children's musical language play as we heard/saw it without adult influence or intervention.

Over two academic years, 2011-2013, author one conducted 108 playground visits, RA one made 46 visits, and RA two made 29 visits to playgrounds for a total of 183 observations. We visited nine different elementary schools (urban, suburban and rural) in two Canadian provinces in order to capture a fair representation of the ways in which children use music in their self-directed play. Student populations among the nine schools differed greatly in terms of ethnic diversity: some schools served students of mostly Anglo backgrounds with small minorities identifying as First Nations, while other schools had significant percentages of recent immigrants and former refugees. In only two schools did we regularly hear minority languages on the playground. At one location a large group of Nepalese girls played exclusively in their first language except when game rules needed to be negotiated at which time they switched to fluent English. At another location a group of young boys consistently used their Mandarin language with one charming exception: they employed what sounded to our Western ears as rhymes to signal play moves, always ending with a distinctly English "go". There were probably many more instances of multicultural resources being accessed in play. We did not intrude upon the many small groups of children (particularly girls) who gravitated to the far corners of playgrounds because we recognized their clear desire for privacy. Song/dance/drama routines were often being rehearsed in these private spaces, and it is likely that shared-language alliances accounted for some of these groupings. 
We walked around the playgrounds keeping a low profile and listening to all instances of vocalization. Children, if they noticed our presence, clearly assumed we were substitute teachers and occasionally approached to ask "who are you in for" or to seek assistance with squabbles or minor injuries.

We scribed all instances of vocal soundings from the non-verbal vocables that accompany virtually every physical movement to playful language use, raps, chants, vocal utterances, improvised commentaries and full songs and musical games. We employed graphics and musical shorthand notation in the field and wrote up detailed field notes immediately after each visit while the sounds were still fresh. From this large body of data we focus here on languaged vocalizations.

\section{Playground Language Play}

School-aged children (ages 5-12) sing and vocalize extensively during play as part of a constant swirl of multimodal expression and communication: gesture, movement, chant, and song appear integral to their play (Marsh, 2008). Additionally, children sometimes play more formal musical games and chants, especially while skipping, executing hand-claps, and playing games such as the currently popular Cup Game which children have extracted from the Hollywood movie Pitch Perfect. Traditional children's repertoire and popular culture material are both found in abundance, often mashed together. The fragmentary nature of much of this musical play is noteworthy: children often move from one play pursuit to another with dizzying speed.

While children's "sonic communication" (Finnegan, 2002, p. 70) includes both languaged and non-languaged vocal sounds, our focus here is on languaged soundings. We specifically attend to language use that features metric, rhythmic and/or tonal elements, that is, musical qualities in language: "the phenomenological intertwining of musical and linguistic parameters in situated acts of communication" (Feld \& Fox, 1994, p. 30).

We have chosen to convey approximations of this musical language play through conventional musical notation with some additional graphic indicators and with narrative description. We recognize the danger that music notation will distort "by sieving out the features most easily captured by this system" (Young, 2006, p.273). We also note that there is not a standardized notation for movement analogous to that for music. We rely on verbal description to convey the multimodal nature of these soundings.

\section{Individual Language Play}

The following examples of solo voice play are representative of hundreds we documented. Our interpretations of children's intentions are speculative based on observations that can only be partial because the participants are in constant movement and often their soundings represent one of several events occurring simultaneously.

Musical language play for personal comfort or pleasure. In these examples the children appear not to be seeking playmates to interact with or even to serve as an audience. Rather the soundings seem to provide amusement or accompaniment. 


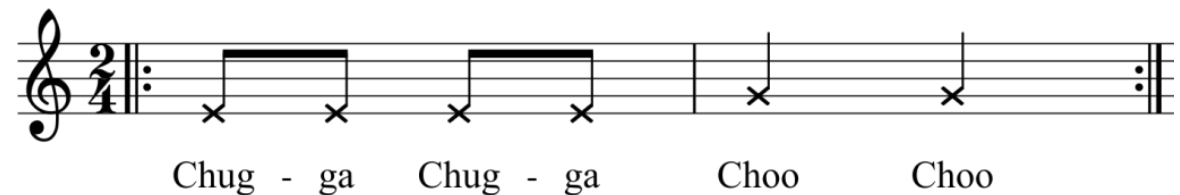

- A kindergarten boy chanted this in strict rhythm coordinating his train-like movements with his vocalizing. The buzzer indicating the end of recess seemed to have been the impetus for this event. We noted four perfect reiterations before he was engulfed by other children.

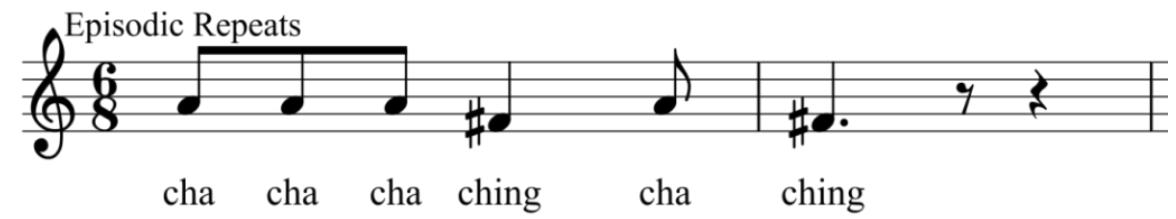

- A Grade 2 boy sang this motif as he hurled his body onto a skinny ice patch for his turn at a micro-slide. He sounded his running start with the first five syllables and hit the ice for the actual slide on "ching". Each of his peers accompanied his/her slide with various high pitched, non-languaged vocables, but this boy resolutely stuck to his personal rhyme to mark his slide each time his turn arrived.

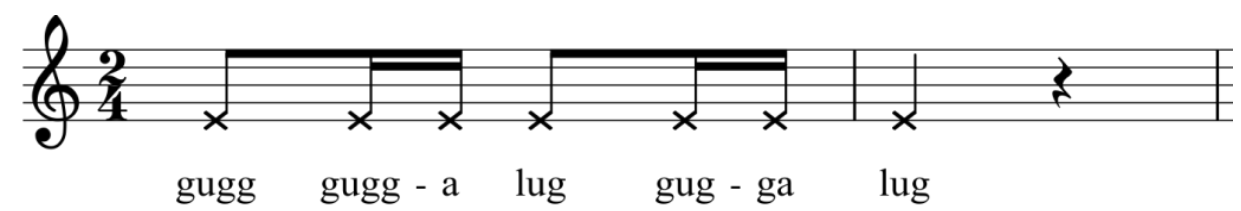

- A Grade 1 girl ran by chanting this in our direction. While it was over in a nano-second it caught our ear because of the sense of purpose and delight she communicated.

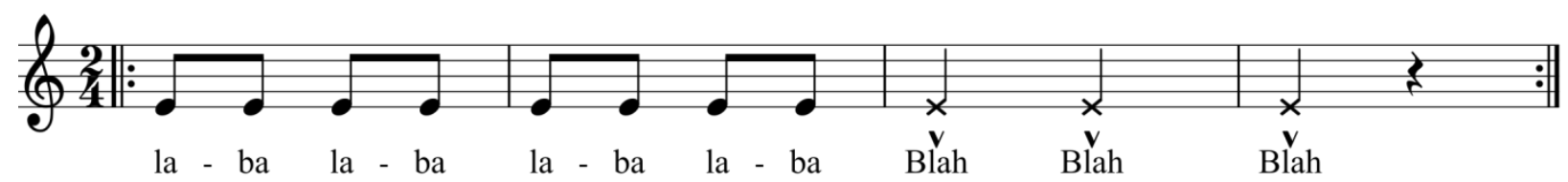

- A Grade 3 boy repeated this refrain several times as he sorted through his deck of hockey trading cards. 


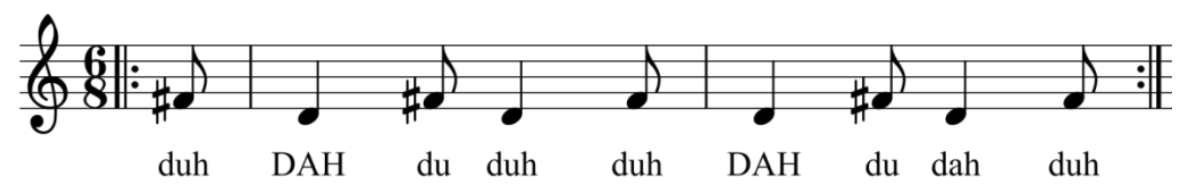

- A Grade 3 boy repeated this refrain, kicking a cement curb on each accented beat. He seemed oblivious to the swirl of play around him.

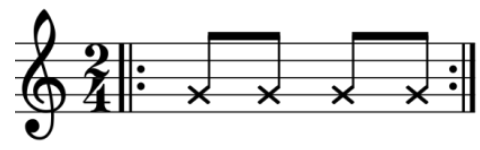

pigg-ley wigg-ley

- A small boy chanted this tiny riff repeatedly while swinging, maintaining a strongly metric feel. His swinging was not coordinated with his chanting.

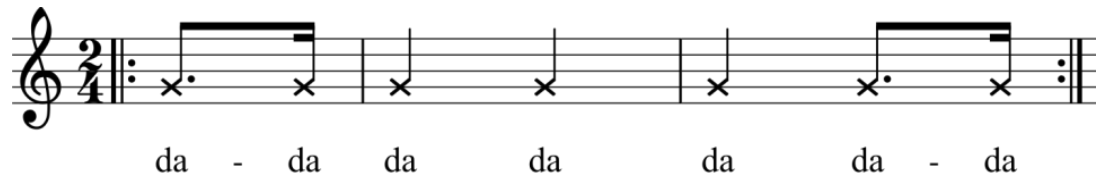

- A Grade 1 boy chanted this riff continually, his walking coordinated with his vocalizing. The sense of metre was particularly strong because the child, stepping perfectly on every beat, emphasized the third and fifth "da".

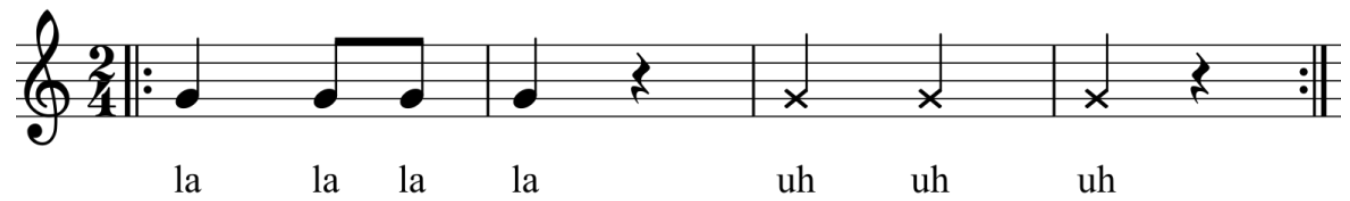

- A Grade 2 boy walked by, repeating this riff, with exaggerated body movements as he went to line up at the end of recess. The 'la' part was in heightened speech, not sung to a specific pitch, but in a higher vocal register and more elongated than speech. In contrast the ' $u h$ ' was done in a low, guttural vocal register, with impressive foot stomping for emphasis.

yo-ga

- A Grade 3 girl moved about on a Play-motion structure, accompanying her physical play with one word, yoga. She chanted it in various rhythmic configurations, sang it in various pitch combinations, and stretched it in endless improvised variety, experimenting with various voice registers. She was in 
constant physical motion. It is impossible to determine whether the voice was instigating the movement or the reverse.

Musical language play for self-announcement. In these excerpts children, while playing alone, appear to want to be noticed or to call others' attention to something.

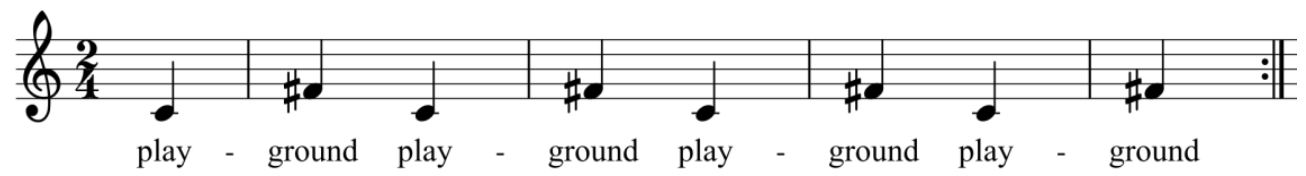

- A Grade 6 boy sang this motif as he rushed from the school building to claim a particular game space. These two pitches in combination are tricky to sing, yet he executed it perfectly, eight times in all. He was at the front of a pack of peers who charged after him with purpose.

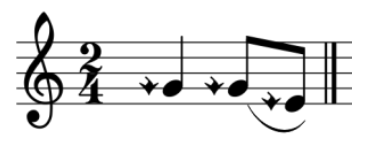

Free swi-ing

- A Grade 2 boy sing-chanted this motif multiple times, indicating the empty swing beside the one he was enjoying. The motif maintained its metric and rhythmic shape, while tonally it moved between precise pitches and less precise heightened speech. We heard six reiterations before he scampered off.

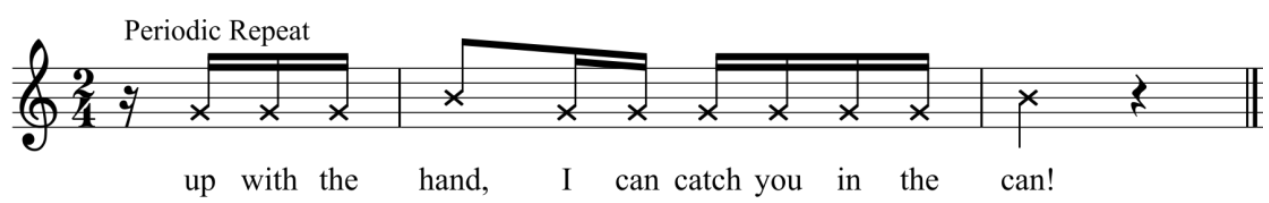

- A group of Grade 4 boys were playing a game of Four Square. One boy, awaiting his turn, rapped continually as he executed stylized hip-hop culture moves. The words alternated between inaudible improvised bits and some approximation of this motif. The peer group paid this fluid performer no overt notice. 
Musical language play to initiate socialization. In these excerpts the solo vocalizers seemed to want to engage a peer or peers in play.

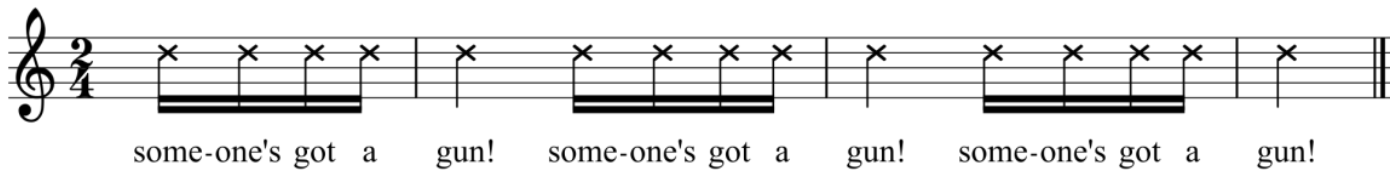

- A Grade 2 boy yelled this three times amidst the mad swirl of bodies, apparently trying to initiate a new chase game, or to insert himself in an already-established one.

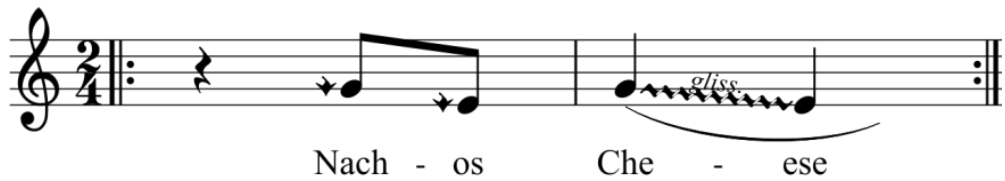

- A Grade 3 girl played with these words in heightened speech as she re-entered the school following recess. After several repetitions she reached out and ruffled a male peer's hair while playfully chanting the motif. Magically, two other children picked up the refrain as they moved back to class.

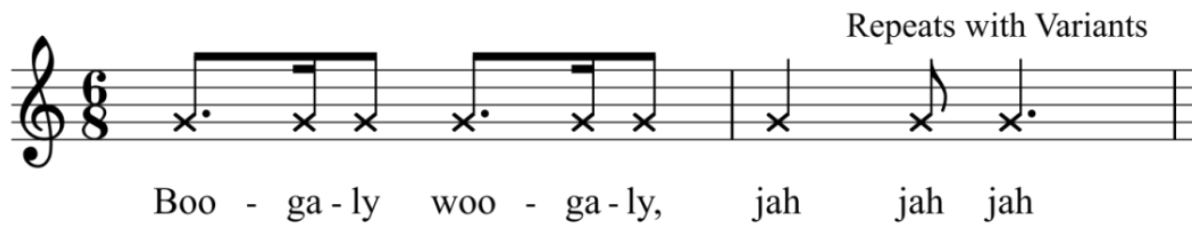

- A Grade 3 boy chanted this several times, complete with crazy, rolling eyes and exaggerated Zombie arm movements as he chased a girl through the crowded playspace.

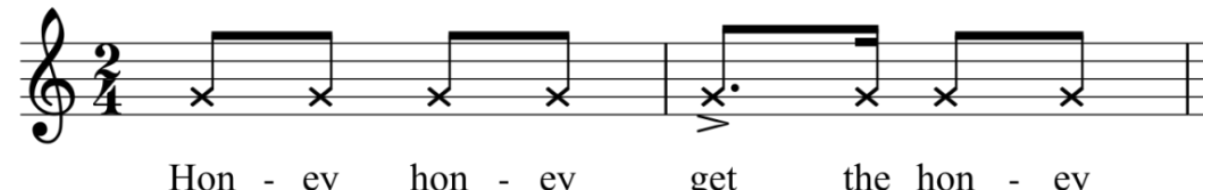

A Grade 1 girl ran by chanting this refrain. Amidst the mass of moving bodies it was impossible to discern whether she had attracted a playmate or was still on the hunt.

Analysis of Individual Language Play

It is commonly thought that language play is the domain of preschoolers and that school aged children have left it behind. Our observations refute that perception. We 
document copious amounts of musically-inflected language play at all age levels on K-6 playgrounds when girls and boys are engaged in self-directed play.

The above examples illustrate individual children playing with language for amusement, comfort, self-expression and self-announcement, and to invite social interaction. A rich range of non-semantic syllables, in addition to language with both literal and metaphoric meaning is evident. This language play is unselfconscious: children use their voices and their bodies holistically to express and represent. It clearly provides pleasure, and it contributes to creating and sustaining imaginary worlds. Cook (2000, p. 22) argued that the repetition, steady beat, and memorable rhymes of language play create a formal regularity which is "internally regulative" as well.

In their language play children also experiment with rhyme and alliteration, blending and segmenting to fit their play purposes. As they manipulate subtle nuances of pitch and duration and decontextualize and recontextualize discursive units they manipulate the sound structure of language.

\section{Language Play in Social Contexts}

Overtly social uses of musical language play are constant on the school playground. To the adult observer these social language inventions appear to serve a variety of purposes, some of which we catalogue here. We emphasize the multivalent nature of this play, which our linear descriptions might tend to obscure.

\section{Accompanying and Framing Play}

Musically vocalized use of peers' names is a constant feature of group play, and seems not to diminish with age. Sometimes these calls are very fast

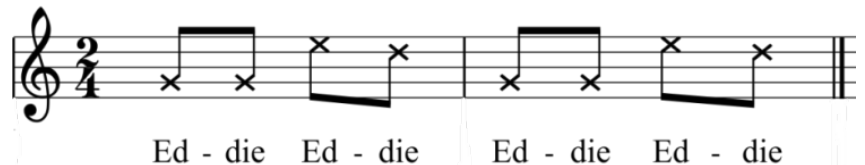

and often they are used to tease

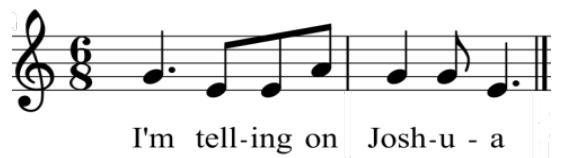

or to cheer

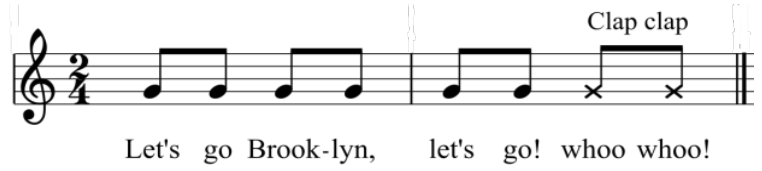


Other times the name play is more extended.

Em-i ly.

- A group of about ten girls and boys was playing Sandman on a climbing structure. Emily was "It" and several girls called her name, somewhat randomly. Quickly this call morphed into a musically organized riff:

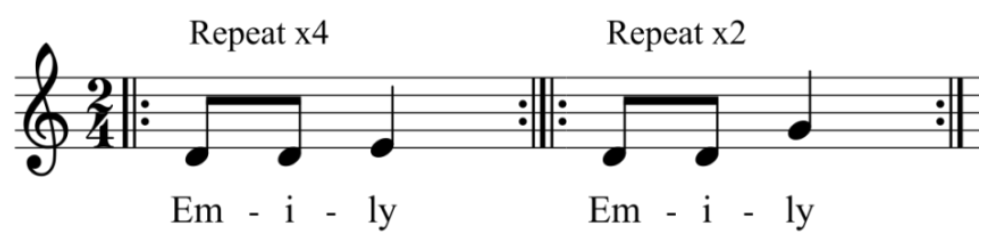

After about four repeats of "Em-i-ly" on a M2 interval (the first two notes of a Major scale), the riff grew to a P4 interval (a jump from the first to the fourth note of a Major scale). A boy joined the call and initiated a speeding up of "Em-i ly". The distinct pitches soon disappeared and the accelerando continued, until Emily was safe.

Sometimes children relied on age-old childlore, such as

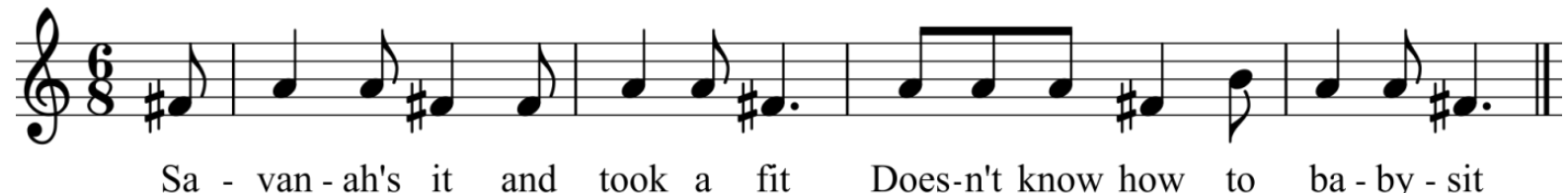

to clarify who is "It", or

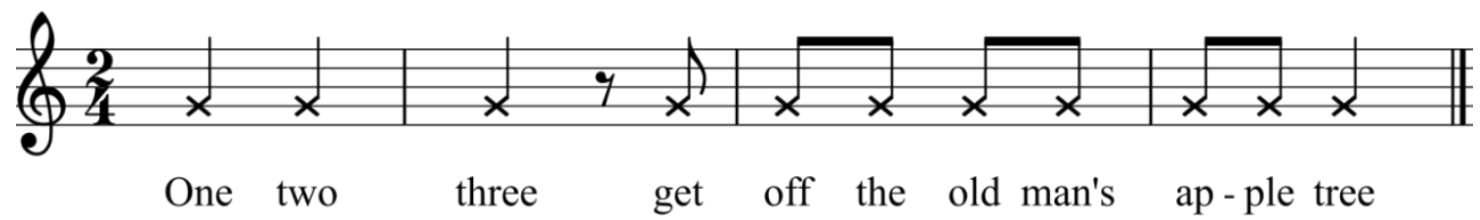

which served as a collective taunt to the new "It". Such inherited chants seemed to bubble up spontaneously. They must, we think, be instigated by one child, yet, within a nanosecond the entire play group was chanting vigorously.

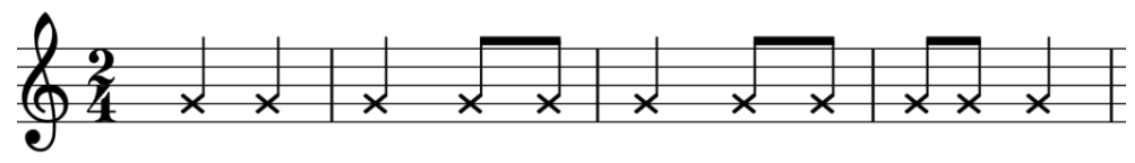

Go, go, go Char-lie, go. Char-lie, do it now 
- The rope game, Helicopter had been popular at one school since the snow melted in early April. "It" skims a long rope, just touching the tarmac, around a circle of players and each player jumps over the rope as it passes by. One group of 11 and 12 year-old players periodically chanted this rhyme, inserting the name of whoever is "It". The chant recurred unpredictably, but each time it reappeared it featured a fast tempo, a tightly synchronized rhythmic organization, and a hearty vocal delivery in heightened speech, very distinct from everyday talk. The variation on the more typical "Let's go Charlie, Let's go" was perfectly maintained throughout 20 uninterrupted minutes of Helicopter.

Beyond the use of names, children created endless opportunities to shape their play with musically inflected language.

- Two Grade 5 girls were engrossed in a conversation. One girl opined that "it's between mediocre and yuck", to which her friend chanted, pitch rising with each of several reiterations:

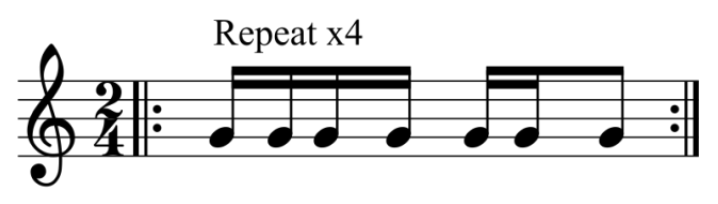

Med-i - o-cre's not a word!

She apparently liked the feel of her short response and so instantly decided to repeat it, elevating it from an everyday spoken response to a musically inflected motif.

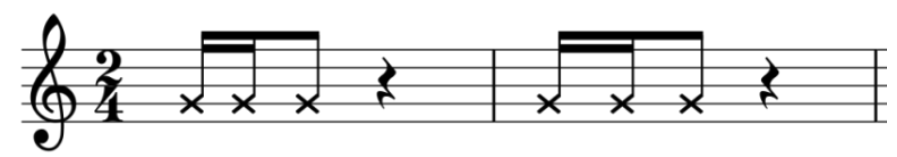

Jel-ly fish Che che che

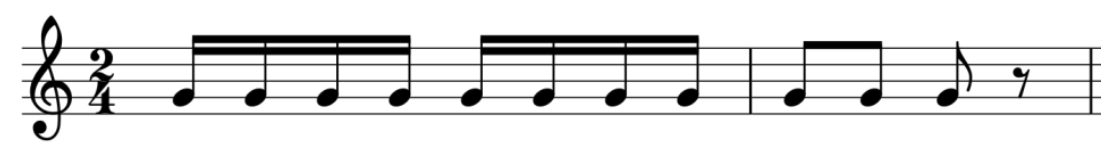

Pea-nut but - ter Pea-nut but-ter jell - y fish

- Kindergarten children chanted various rhythmic phrases involving "jelly fish" and "peanut butter". We assume this was prompted by a shared story or song in the classroom because so many children engaged in this language play in varied simultaneity. Their bodies were in constant motion as they chanted. 
The language play in these examples performed the specific function of making a movement game work.

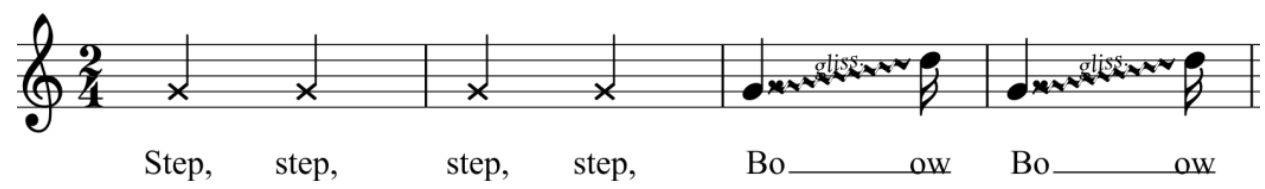

- Two Grade 2 girls, their arms around each other's waists, practiced a stylised coordinated walk using this chanted motif. The elegant bowing was particularly tricky with their arms joined, but they persevered. We heard at least eight reiterations. They appeared delighted with the challenge and their laughter was infectious.

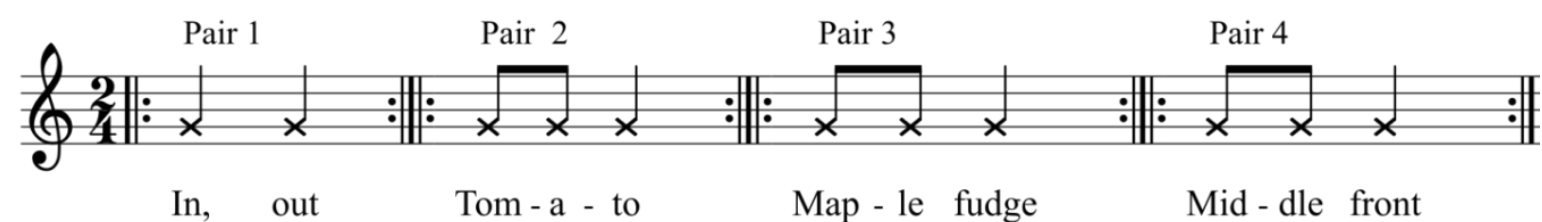

- These motifs, each chanted with a strong metric accent, were created by various pairs of Grades 4 and 5 girls, practicing for a three-legged race. Each pair invented its own code-word, often trying several before discovering one that suited their purpose.

\section{Instructing Play}

We documented periodic instances of children developing ways to teach their peers by using language musically. In each of the following examples the physical play was enabled or improved by the addition of rhythmically chanted or sung instructions.

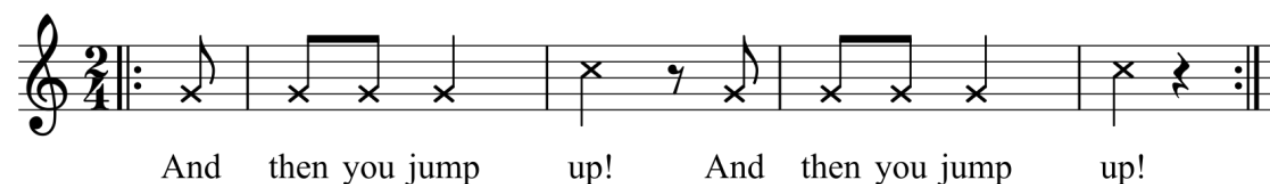

- Two Grade 3 girls were playing at the intersecting side supports of a swing set. One girl was executing an impressive gymnastics manoeuvre on these supports. Her friend tried to replicate the move, unsuccessfully. The first girl spontaneously invented this chant and kept repeating it, first demonstrating and then guiding her friend to success. 


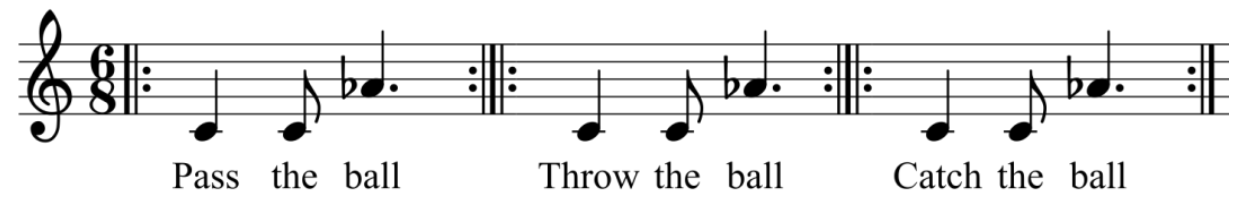

- Several Grade 2 girls were being instructed in a version of Four Square by a Grade 6 girl, Sarah. This game variant involved an obscure requirement to count before throwing the ball. The little ones, clearly confused, counted while Sarah tried to teach the game moves. Recognizing that her charges were not grasping her meaning, Sarah abandoned the counting and began singing the movement directions (pass the ball/ throw the ball/ catch the ball). She maintained an interval approximately a rising $m 6$ (a jump from the first to the sixth note of a minor scale) and a rock steady metre as she moved from square to square and child to child, miming the desired sequence of actions. The children started to get a sense of the game and the leader continued her instructional chant as they practiced play together.

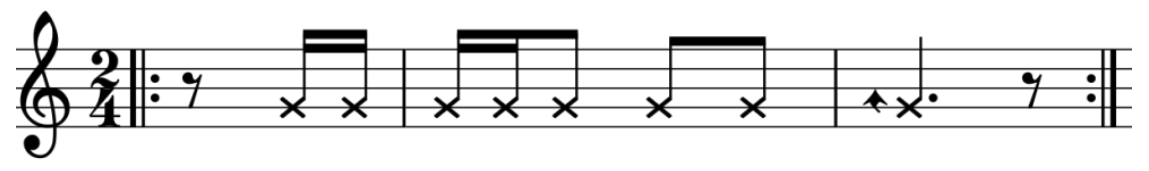

And a lit-tle bit high - er Push!

- A Grade 3 girl pushed a playmate on a swing, chanting this improvised rhyme repeatedly. On push, she provides a strong physical push and her voice rises dramatically in pitch. Push arrives perfectly each time, indicating that this child was adjusting the tempo of her rhyme subtly to accommodate the small timing discrepancies in the swing's trajectory.

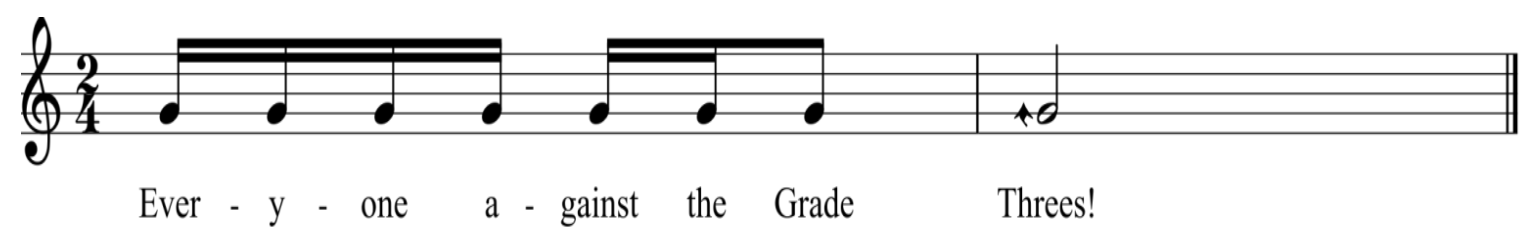

- A Grade 4 boy, a regular player in a ubiquitous soccer game, was clearly frustrated that it was taking longer than usual to get the game launched, because of a larger than usual number of players. He chanted this call several times, using dramatically heightened speech. The observer cannot be sure that these precise directions were followed, but the game quickly got going. 


\section{Performative Play}

While all social play has a performative aspect, we highlight some specific examples that communicated a heightened sense of performance, in the sense of a live presentation for a real or imagined audience. Each of these vignettes was artistic: because they took longer to execute, there was a clear sense of symmetrical form as well as a performative attitude.

- Three Grade 3 boys walked in single file past a large group of boys playing chase. The first boys chants "hi boys", echoed in perfect four-beat metre by the second boy and then the third. The first boy then intoned "bye boys" and again his two pals echoed in perfect metric sequence. The artistry of this performative fragment was striking.

- A group of Grades 4 and 5 boys were playing a well-organized game of Four Square. One boy acted as announcer, providing an entertaining play-by-play of the game. He held one hand as a microphone and adopted an exaggerated broadcaster-style voice. While this vocal play lacked the repetitive patterning characteristic of most of our examples, the young announcer artfully employed such sonic features as pitch inflection, volume, tempo, and rhythmic and metric organization, along with copious paralinguistic vocalizations and a stance and attitude befitting network television.

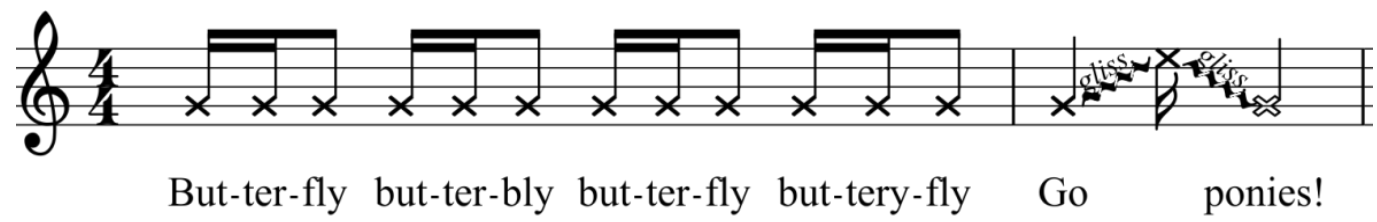

- Four Grade 3 girls performed what they announced as the "Pony Cheer". They formed a circle and sang-chanted Butterfly four times while executing a one-hand stack. When all four hands were stacked they chant-sang "Gooooooooo Ponies" as they pushed off from their circle and twirled away, ballerina style.

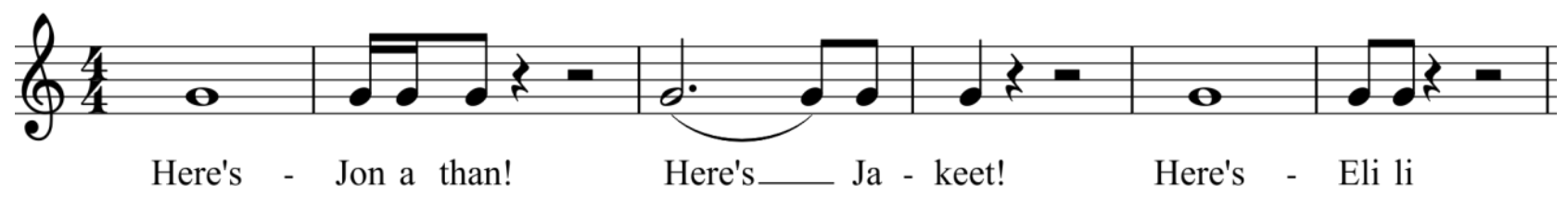

- A group of four Grade 3 boys walked in single file along a railway-tie path that marked off a play area. As the first boy came to the end he jumped off with a dramatic full-body flourish and then announced each of his three mates: Heeeere's Jonathan! Jonathan jumped off grandly. Heeeere's Jakeet! Jakeet exited dramatically. Heeeere's Eli! Eli executed a fancy dismount. Then they dashed off to 
another game. The announcer, in surprising Johnny Carson Show style, used dramatically heightened speech. Moreover his whole body was performing: the grand hand gestures and poised timing commanded attention.

- Two Grade 3 girls approached at the beginning of recess, asking "will you watch our play?" "Of course!" They disappeared, returning three minutes later to perform a short sung play about two bunnies, using their mittens as puppet mouths. The story line was thin, but the energy and performance commitment were impressive. Five minutes later they approached another adult with a completely new improvised opera about two ponies.

\section{Childlore}

The continued existence of inherited childlore-songs, chants, hand-claps, jokes, riddles and so on - is a lovely phenomenon. Despite fears that children's folklore was dying out even in the $19^{\text {th }}$ century (Gomme, 1894, 1898; Newell, 1883) it appears that this body of material has always existed in a state of improvised fluidity. Popular culture references, which have been documented since the early 20th century, are mixed and mashed with pre-existing childlore in a myriad of combinations. Childlore, "children's traditional symbolic culture" (Griffiths \& Machin, 2003, p. 150) represents a dynamic process of transformation rather than one of simple reproduction. Childlore has always been characterized by the existence of multiple variants, from country to country, town to town, and even within a single playground. The popularity of YouTube, launched in 2005, may contribute to standardizing some of this repertoire.

Many elementary educators assured us that none of the old rhymes and songs exist anymore at their school (Marsh, 2008, documented this same phenomenon across five countries). There is a fragmented, sped-up quality to much playground play that creates an impression of disorganization and discontinuity and masks the fact that children's own informally learned culture continues to thrive. It may be played on the perimeters of the playground, away from the noisy masses, or it may be found, sometimes in very short segments, right in the centre of the action. As Campbell (2010) and Marsh (2008) both confirmed, examples are often heard when children have down time, such as lining up or riding the school bus.

We found rich examples of childlore being performed on school playgrounds in the course of our observations. This self-directed musicking trades in rhyme, alliteration, and satisfying segment-repetition coordinated with kinetic movement, gesture, and emotion/attitude. It exemplifies children's expressive practices at their most formalized. We offer three examples representing different categories of childlore.

Count-outs. These rhymes are intended to fairly choose an "It", even though some children quickly learn how to manipulate the rhyme in their favour. The count-out that recurred most frequently in our field notes is Red shoe, blue shoe (sometimes Blue shoe, blue shoe or Black shoe, black shoe). 


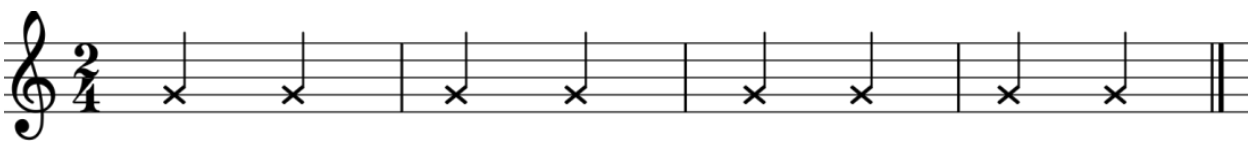

Red shoe, blue shoe. Who's it? Not you

This rhyme requires the players to put one foot into a circle formation. A leader, crouched in the centre, counts off, pointing to each foot in sequence to a steady beat. On each reiteration, one player is eliminated until only "It" remains. We observed children up to Grade 5 using this count-out. The aesthetic arrangement of the circle, with its close physical contact and simple, ritualistic moves, appears very satisfying.

Hand shakes. Hand-clapping games, called hand-shakes on some playgrounds, are usually played by pairs of girls, although we have documented some instances of boys and mixed gender pairs playing as well. One such handshake is Lemonade:
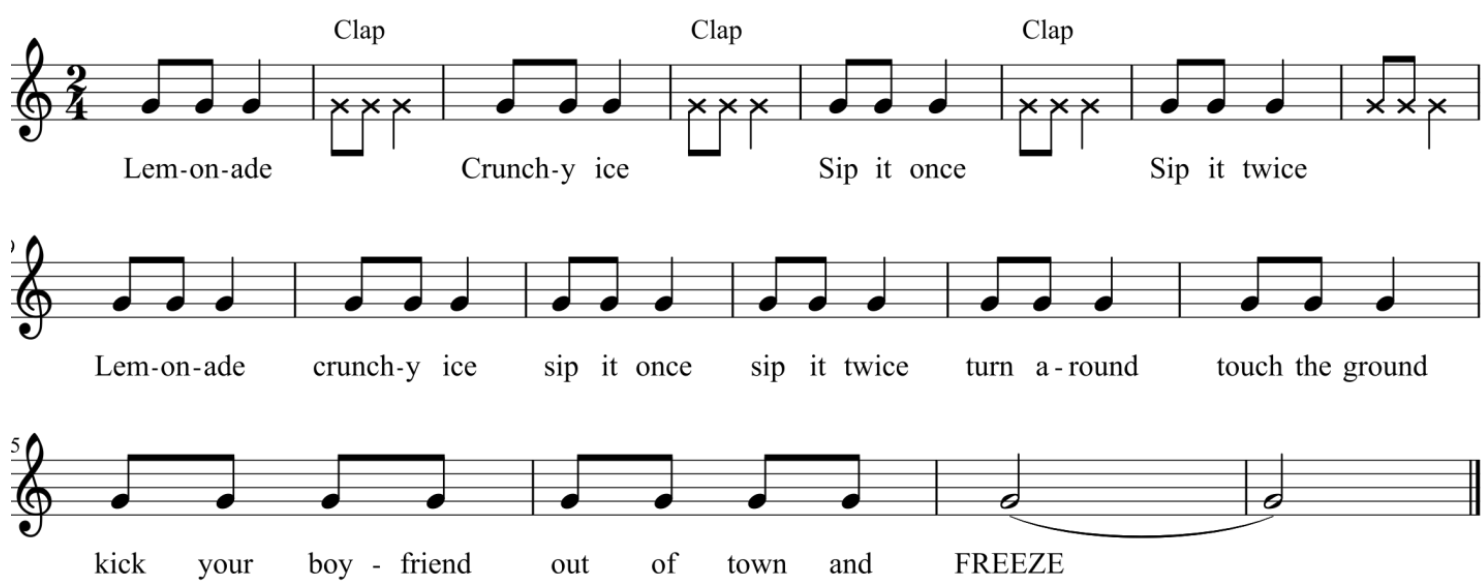

Lemonade features physical moves (turn around, touch the ground, kick and freeze, which is usually a very short staring match, before both players dissolve into laughter) in addition to a self-clap/partner-clap hand pattern. Watching pairs of children who had mastered this game, we were struck by the holistic nature of its execution: language, body rhythms and physical moves were exquisitely synchronized at great speed. We also observed younger children learning such games by intensely watching, miming and mouthing words, then dashing off to practice in private spaces. This apprenticeship model of learning (Harwood, 1998; Marsh, 2008) is important. Children do not just "know" these games, but rather must practice them, which makes the school playground an important site for learning childlore. This is also where childlore is improvised. We documented several variants of Lemonade where the physical moves remained the same, but children varied the language. For example, the "boyfriend" is sometimes a "brother" or a "bully" and the "Freeze" is sometimes changed to "Peace". 
Skipping rhymes. Like handshakes, skipping is usually a female pastime, except in the case of Helicopter, discussed above. One of the most frequent skipping rhymes we documented is Ice Cream Soda. We offer several versions of this rhyme to illustrate the way children recompose the language of their childlore. In some cases we documented multiple variants on the same playground.

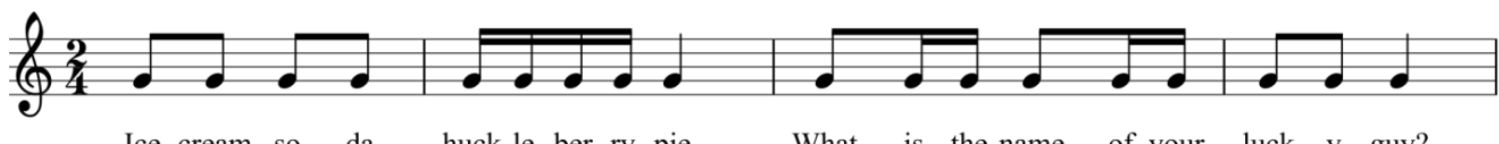
Ice cream so - da huck-le-ber-ry pie What is the name of your luck-y guy?

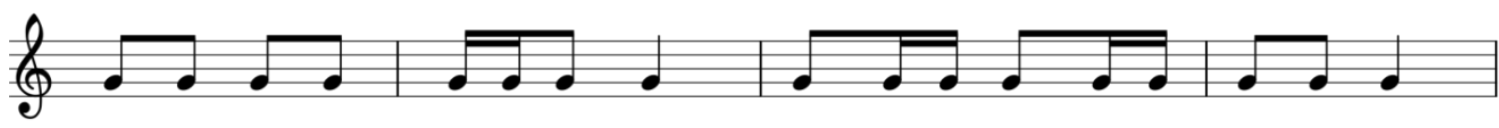
Ice cream so - da lem-on-ade punch Tell me the name of your hon - ey bunch

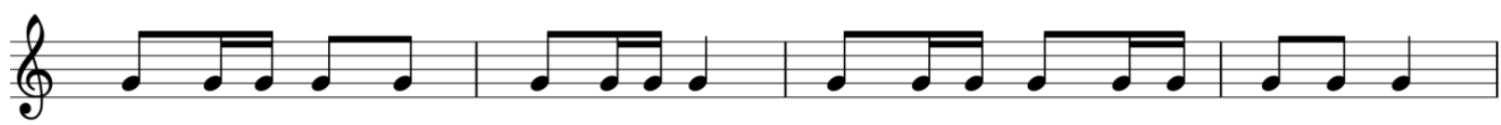
Straw - ber - ry short - cake blue - ber-ry pie What is the name of your favor-ite guy?

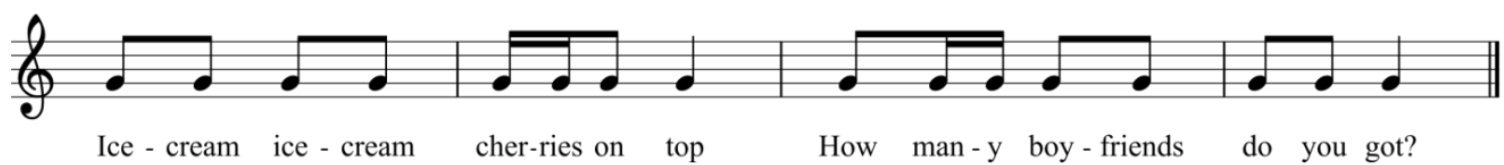

In the first three versions the couplet is followed by chanting the alphabet. If the skipper trips, she must name a boy whose name begins with that letter. In the final variant the couplet is followed by chanted counting, where "It" attempts to keep skipping as long as possible.

\section{Analysis of Language Play in Social Contexts}

We have considered social language play that accompanies and frames children's self-directed play, some of which specifically attempts to coordinate physical movement or to teach specific moves, and some of which is particularly performative in nature. We have also briefly discussed more formal examples of childlore which continues to be transmitted and improvised on school playgrounds. We emphasize that these categories are for adult convenience and do not represent children's notion of their play.

One of the most striking features here is the degree of metric and rhythmic skill required to execute these musical-language expressions. When a game requires a list of names, for example, we marvel at children's seemingly effortless manoeuvring among duple and triple rhythms and varying metric accents which occur in unpredictable and ever-changing order. If, for example, Parker, Amanda, Aram, and Stephanie are being named in sequence, the caller must negotiate four unique rhythmic and accent configurations, demonstrating sophisticated rhythmic perception. 
Another crucial factor in this language play is its embodied nature. The body is central to meaning making and communication: the vocalizer is always also moving. While we are certainly not the first to ask why so much of elementary schooling must be sedentary, our awareness of children's natural proclivity to move while vocalizing has been heightened by our playground observations. As Minks (2002) noted, "All language users rely on metacommunicative prosodic cues (including pitch, rhythm and dynamics) and gesture to make sense of others' speech" (p. 397).

\section{Implications for Practice}

Our examples of musical language play illustrate children's natural inclinations to engage their world multimodally, through gesturing, moving, gazing, speaking, vocalizing and singing. The self-directed play in which these soundings were embedded is rife with what Wolfe and Flewitt (2010) termed "collaborative multimodal dialogue . . . inter-subjective meaning-making processes that occur through interaction and joint engagement in activity" (p. 388). We urge literacy educators to acknowledge and utilize children's fluency with these "out-of-school literacies" (Jewitt, 2008, p. 242) and we briefly describe pedagogical openings where this might occur.

\section{Situated Practice}

In the experiencing phase of Cope and Kalantzis's (2009) multiliteracies pedagogy they suggested grounding new learning in the children's authentic experiences and actions. Here is a perfect place to invite children to share their prior understandings through performative means, inventing chants, movement sequences, raps, sound bites and more. Regular opportunities to perform their ideas multimodally will encourage children to share their cultural and linguistic diversity and their childlore and pop culture knowledge. When educators provide these openings they enrich the speaking/listening aspect of language learning and honour and extend children's communication skills.

\section{Form-based Language Play}

We know that children unconsciously experiment with rhyme and alliteration, intonation, inflection, and flow as they sound their play. We observe their predilection to manipulate speech sounds and to adhere to a constant, steady beat, and their love of repetition of rhymes, which creates formal regularity. The rhythmic aspect of language play makes it socially interactive as well as personally pleasurable. Importantly, this language play continues throughout the elementary years. We believe that it is crucial for educators to inject playful approaches to language learning where appropriate. "Knowing a language, and being able to function in communities which use that language, entails being able to understand and produce play with it, making this ability a necessary part of advanced proficiency" (Cook, 2000, p. 150).

When children have opportunities to create new words to pre-existing rhymes, riddles, proverbs, advertisements, poems, and songs they are free to generate "imaginary worlds, situations, characters and events" (Cook, 2000, p. 48). The predictability provided by the formal structure of a "knock-knock" joke, a familiar rhyme or a favourite 
story or song provides a corresponding freedom to experiment with language choices, inventing new creations tailored to the local context. The possibility to be humorous or absurd is deliciously motivating.

Form-based language play invites a different and potentially more imaginative exploration than the meaning-based language use that language education emphasizes. Form-focused language play invites personal invention and the opportunity to adopt various voices. The creator can imply or contradict and is free to indulge the natural instinct to manipulate language for the pleasure of its sound properties. Rich language experiences occur when children are invited to generate and to co-operatively perform their created verses to accompany classroom rituals, to commemorate significant events or to explore current issues.

Language play, a culturally-derived form of social knowledge, enhances language fluency through inviting children's creativity, both individual and collective. Inserted authentically into classroom situations, it provides teachers with a compelling tool for engaging learners as confident, agentive meaning-makers. Researchers have proposed that children's play is linked with children's cognitive development, creativity, and language use (Bodrova, 2008; Samuelsson \& Carlsson, 2008; Vygotsky, 2004). Building upon these natural literacy events flowing from children's multimodal vocal play will support the development of their language and literacy fluency within formal educational contexts.

\section{Acknowledgements}

Research Assistants Katherine Thompson and Melissa MacRae were supported by the MCRI, Advancing Interdisciplinary Research in Singing (AIRS), funded by the Social Sciences and Humanities Research Council of Canada.

\section{References}

Alcock, S. (2008). Young children being rhythmically playful: Creating musike together. Contemporary Issues in Early Childhood, 9(4), 328-338.

Biesty, P. (2002). Where is play? In D. Lytle (Ed.), Play and educational theory and practice (pp. 43-55). Westport, CT: Praeger.

Bodrova, E. (2008). Make-believe play versus academic skills: A Vygotskian approach to today's dilemma of early childhood education. European Early Childhood

Education Research Journal, 16(3), 357-369.

Campbell, P. (2003). Ethnomusicology and music education: Crossroads for knowing music, education and culture. Research Studies in Music Education, 21(1), 16-30.

Campbell, P. S. (2010). Songs in their heads: Music and its meaning in children's lives, (2nd ed). New York, NY: Oxford.

Cook, G. (2000). Language play, language learning. Oxford, UK: Oxford University Press. 
Cope, B., \& Kalantzis, M. (2009). Multiliteracies: New literacies, new learning. Pedagogies, 4(3), 164-195.

Dissanayake, E. (2000). Art and intimacy: How the arts began. Seattle, WA: University of Washington Press.

Dissanayake, E. (2001). Aesthetic incunabula. Philosophy and Literature, 25(2), 335346.

Dissanayake, E. (2009a). Bodies swayed to music: The temporal arts as integral to ceremonial ritual. In S. Malloch \& C. Trevarthen (Eds.), Communicative musicality: Exploring the basis of human companionship (pp. 533-544). Oxford, UK: Oxford University Press.

Dissanayake, E. (2009b). Root, leaf, blossom or bole: Concerning the origin and adaptive function of music. In S. Malloch \& C. Trevarthen (Eds.), Communicative musicality: Exploring the basis of human companionship (pp. 17-30). Oxford, UK: Oxford University Press.

Dissanayake, E. (2011). Prelinguistic and preliterate substrates of poetic narrative. Poetics Today, 32(1), 55-79.

Feld, S., \& Fox, A. (1994). Music and language. Annual Review of Anthropology, 23, 2553.

Finnegan, R. (2002). Communicating: The multiple modes of human connectedness. London, UK: Routledge.

Gomme, A. (1894 \& 1898). The traditional games of England, Scotland, and Ireland Vol I. \& II. London, UK: David Nutt.

Griffiths, M., \& Machin, D. (2003). Television and playground games as part of children's symbolic culture. Social Semiotics, 13(2), 147-160.

Harwood, E. (1998). Music learning in context: A Playground tale. Research Studies in Music Education, 11, 52-60.

Hurdley, R., \& Dicks, B. (2011). In-between practice: Working in the 'thirdspace' of sensory and multimodal methodology. Qualitative Research, 11(3), 277-292.

Jewitt, C. (2008). Multimodality and literacy in school classrooms. Review of Research in Education, 32, 241-267.

Jewitt, C. (2009). An Introduction to multimodality. In C. Jewitt (Ed.), The Routledge handbook of multimodal analysis (pp. 14-27). New York, NY: Routledge.

Kress, G. (2010). Multimodality: A social semiotic approach to contemporary communication. London, UK: Routledge.

Malloch, S., \& Trevarthen, C. (Eds.). (2009). Communicative musicality: Exploring the basis of human companionship. Oxford, UK: Oxford University Press.

Marsh, K. (2008). The Musical playground: Global tradition and change in children's songs and games. New York, NY: Oxford University Press.

Minks, A. (2002). From children's song to expressive practices: Old and new directions for the ethnomusicological study of children. Ethnomusicology, 46(3), 379-408.

Newell, W. (1963). Games and songs of American children. New York, NY: Dover. (Original work published in 1883 and 1903). 
Patel, A. (2008). Music, language, and the brain. New York, NY: Oxford University Press.

Pellegrini, A. (2009). Research and policy on children's play. Child Development Perspectives, 3(2), 131-136.

Samuelsson, I. P., \& Carlsson, M. A. (2008). The playing learning child: Towards a pedagogy of early childhood. Scandinavian Journal of Educational Research, 52(6), 623-641. DOI: 10.1080/00313830802497265

Small, C. (1998). Musicking: The meanings of performing and listening. Middletown, CT: Wesleyan University Press.

Van Leeuwen, T. (2009). Parametric systems: The case of voice quality. In C. Jewitt (Ed.), The Routledge handbook of multimodal analysis (pp. 68-77). New York, NY: Routledge.

Vygotsky, L. S. (2004). Imagination and creativity in childhood. Journal of Russian and Eastern European Psychology, 42(1), 7-97.

Wolfe, S., \& Flewitt, R. (2010). New technologies, new multimodal literacy practices and young children's metacognitive development. Cambridge Journal of Education, 40(4), 387-399.

Young, S. (2006). Seen but not heard: Young children singing and educational practice. Contemporary Issues in Early Childhood, 7(3), 270-280.

\section{Author Biographies}

Dr. June Countryman recently retired from the University of Prince Edward Island where she was an Assistant Professor in music education. Her Ed.D is from OISE/ University of Toronto. She continues to pursue research exploring children's informal musicking on school playgrounds and adolescents' deep musical engagements.

Dr. Martha A. Gabriel is a Professor at the Faculty of Education, University of Prince Edward Island. Her research areas include exploring multimodalities/multiliteracies, and examining children's musicking in informal environments, in particular, during the early years.

Drs. Countryman and Gabriel are co-investigators in the AIRS Major Collaborative Research Initiative (MCRI) entitled Advancing Interdisciplinary Research in Singing (AIRS), funded through the Social Sciences and Humanities Research Council of Canada (SSHRC) directed by Dr. A. J. Cohen, UPEI. [www.airsplace.ca] 